\title{
NEW TRENDS IN MICROECONOMICS THEORY
}

An economist is a professional paid for making wrong economic decisions...

While organising a successful business system we can expect that any small internal or external changes can trigger disproportionate responses within the network of international connections and business perspective of the investors. To assume the future development of economy is a problem, nevertheless the economists are trying to find a way of applying the new knowledge if they want to predict the future of certain situations in the real economic system.

\section{Mathematics that has not helped microeconomics}

In economic theory and especially in micro economy the verbal description of events explaining the causal relations was replaced by mathematical language using small changes, pseudo-statistics relations, and analysis of the historical data and tests of hypothesis.

The view of the dynamics of the economic system has disappeared from the economics textbooks. Instead of searching the answer for the content questions the explanation concentrated on the used tools and in this way the relation between the theory and the reality got lost. Neoclassic microeconomics describes the economic system in the following way:

- determination of the optimal conditions (where inputs are used to produce maximal outputs) at which the situation is the equilibrium of defined values,

- following these conditions the microeconomics theory can show what processes appear if the system is not in the optimal position and how it will follow the path to the equilibrium,

- the initial optimum does not have to be so called Pareto's and microeconomics can decide if it is that or not,

- if there is not an optimum then microeconomics can suggest the Pareto's processes for improvement or it can demonstrate which real processes can lead to the Pareto's improvement.

While predicting economic events the neoclassical theory supposes that people will behave as they did in the past, which means the condition of ceteris paribus is met. This condition enables us to find out the impact of a chosen individual value on the change of examined value in the complicated circumstances of dynamic systems. If we create an economic (or other) theory it does not mean that we take into account all possible aspects of the described event. The opposite is true, there is a need to focus on some aspects that can be described by abstract simplicity while we suppose that all other aspects are neutralised, i.e. they are constant. As the changes of economic events in time and area are continuous and the situation is a result of parallel appearing changes of different factors, it is valid that:

- The stage of a given event can be defined only with regards to the real defined time frame that means that in the time of gaining the results the event is actually history because it had changed and

- The change can be defined as a total change which is a result of the influence of all relevant factors simultaneously. If we are interested in the relation of individual factors and their impact on the total change we have to follow ceteris paribus which means that we take other factors in the given research as constant.

Used models created on the physics-mathematics analogy exploit very often the principle of the exact natural science and they are seeking for validity in the economic systems (e.g. equilibrium principle). In this analogy we can imply the results from the initial assumption using the algorithmic solution.

A part of the microeconomics theory halted on the assumption of the static view which does not reflect the today's reality. The economist very often works with models created on the base of physics-mathematics analogy using the principles of the science and they are seeking for similarity with physics (e.g. the equilibrium principle).

There are two reasons why the apparatus of science can not be transferred to the economic science.

- The first reason is the lack of forecasting data. In the economic system historical data has little importance in the prognosis as the system is changing its quality in the time frame. If we concentrated on the history of the London Stock Exchange the price development calculated on the base of 1694 cannot be any help for decision making process. The capital market in the 17 th century was totally different to that in 19th century. The 1990s brought so many changes that those 10 years old data cannot be used reliably. If we wanted to predict the development of a certain investment fund with $95 \%$ reliability we would need at least 400 years history of the firm.

\footnotetext{
* Juraj Dubovec, PhD. ${ }^{1}$, Tibor Hlačina ${ }^{2}$

${ }^{1}$ Faculty of Management Science and Informatics, University of Zilina, Slovakia, E-mail: dubovec@fria.utc.sk

${ }^{2}$ European Polytechnical Institute, Kunovice, Czech Republic, E-mail: hlacina@vos.cz
} 
- The ability of the market participants to integrate information and learn from experience is the other reason. While predicting economic events we assume very often that people will behave as they did in the past. The ability of the market participants to integrate the information and learn from experiences very often does not enable the prediction as we go from known causes to the unknown results.

When we use these deterministic models, all information is stored in the initial conditions and without knowing the historical context we cannot answer the questions of the real economic life.

\section{How to proceed?}

This stage should motivate us in searching new theories explaining the problems of the real economic life. Briefly, I will introduce the main ideas of this scientific movement and I will focus on their usage in the economy and the theory. New terms as catastrophe theory, chaos and complexity are emerging in economic literature too. The basic question is if it is just a fashionable trend in the frame of the publicity activity of writers or if we are witnessing a new period of thinking in economic theory.

\section{Catastrophe theory}

If we press a straw at both ends it gets a bit shorter but if we press more it bends. The mathematician R. Thom created the theory describing such sudden change naming it "catastrophe".

In this case we talk about the change of qualitative properties of the system agents during the jump changes. The theory is focused on phase transfer during which the bifoculiar effect appears. The application of bifoculiar theory while researching the jump change (catastrophes) in mechanical, physical, biological, economic and ecological systems creates the basic idea of the catastrophe theory.

In spite of the attractive name the theory of catastrophe can tell little about the events in economies. In cases of thousands of elements influencing each other the collective organisation and behaviour is important. The usage of the theory of catastrophe for description of systems where there are networks (e.g. economic systems) is limited, as the jump changes are not typical for the economic system.

\section{Chaos theory}

In the real economic life there are many situations where uncertainty of our knowledge of the system stage at any given moment can lead to the loss of information about the future system stage very quickly. Thus the present stage can develop rapidly to a very different future stage. Such systems are thought to be chaotic and their influence is responsible for the complexities of economy all the way through to those of climate change. In such situations there is no halfway house, as it were, where we can predict with certainty the rules required for any such unknown changes thus our ability to forecast is limited.

The chaos theory has its origin in the work of the French physician H. Poincare (scientists realized the importance of his work only after 1980). If something is chaotic then, similarly as with a roulette ball the final position of the ball is unpredictable. Thus forecasting the future of any chaotic system is practically impossible. In the case of natural chaos, e.g. earthquakes etc. we have what we call The Butterfly Effect where the flutter of a butterfly wing in one location can cause a hurricane in another.

In the complex dynamic system there are points of non-stability - critical moments where a small movement can cause big results. This so called butterfly effect is very often referred to as the sensitive dependence on the initial conditions. In the economic agent's behaviour, the sensitive dependence on the initial conditions is an unavoidable result due to the connection of events of micro and macro economy.

In the situation of a „strongly imbalanced" condition of the system, small change or deviation can grow to huge waves damaging the structure. This is a world of instability, disequilibrium, and turbulences in "strongly unstable stages" and non-linear events with the complex feedback.

The chaotic process seems to be extravagant even if the rules on which it is based are simple. The research discovered the mathematic features of the chaos in many areas. Some scientists believed that with the help of the chaos theory they could understand the wild falls in the financial markets. The chaos theory can explain the simple unpredictability, (why a small reason can result in serious ends) but it cannot explain the trends towards the revolutionary changes where the dimensions of the result have no relation to the dimensions of the initial causes.

The economic science using the knowledge of the chaos theory can only predict the direction (not the range) of a change resulting from the specific costs and incomes. What will happen cannot be predicted from the point of the direction (up, down) nor regarding the probable dimension.

\section{The study of the complex systems concentrate}

On the disequilibrium situation where the history is very important. In order to understand the irregular surface of the broken brick we need to know the history of its creation, the form of the snow flake with its details can make sense if we follow the history of its growth during the slow freezing of the mist.

The disequilibrium problems cannot be simulated with equations and we need to choose other approach - we should use the equation of games. The historical rhythm of the world is determined by the natural gathering of tension in the global policy- economic system and its release. The economic force of each nation grows or declines in time. Some states having the power position 
do not have relevant economic power and other states (having the greater economic potential) are looking for a larger influence to enforce their interest. The result of this situation is that the tension is growing and sometimes it is released through the war after that the influence of each state is in an approximate equilibrium responding to their real economic power.

Many theories and methods used in the area of complex systems did exist earlier in the frame of cybernetics and the general system theory and they were also involved in the general theory of evolution of systems from the history point of view. The basic philosophy is that even if the world is very complex, we can find the organisational types that can be described using the general principle independently of the specific areas we are looking at. The system theory is focused on the structure and the model of the organisation and the cybernetics focused on the organisation functions and the communication. The organisation stability is what changes the gathering of people into a system. This evolutionary theory assumes that we can understand the systems only by analyzing the process within which the systems originated. The basic mechanism of evolution - variance and selection continuously create new systems from their mostly simpler predecessors.

Using this new tool we should be able to predict better the range of changes resulting from the individual changes in costs and incomes in the separated markets in the dynamic environment.

\section{References:}

[1] AVGOUSTINOS, A.: Blunder (in Slovak), Vel'ký omyl, Iris Bratislava, 2004

[2] BUCHANAN, M.: World-wide princip, Baronet Praha, 2004

[3] COVENEY, P.: Between chaos and order (in Czech), Mladá fronta, Praha 2003

[4] DUBOVEC, J.: Microeconomics (in Slovak), EDIS, ŽU Žilina, 2004

[5] ETZIONI, A.: Moral dimension of economics (in Czech), Victoria Publishing, Praha 1995

[6] FENDEK, M.: Quantitative microeconomics (in Slovak), IURA Edition, Bratislava 1999

[7] RIDLEY, M.: Genesis of virtue (in Czech), Portál, Praha 2000 